\title{
Intra- and inter-individual variation in the foraging ecology of a generalist subantarctic seabird, the gentoo penguin
}

\author{
Elodie C. M. Camprasse ${ }^{1, *}$, Yves Cherel ${ }^{2}$, Paco Bustamante ${ }^{3}$, John P. Y. Arnould ${ }^{1}$, \\ Charles-André Bost ${ }^{2}$
}

\begin{abstract}
${ }^{1}$ Deakin University, School of Life and Environmental Sciences (Burwood Campus), Geelong, 3220 Victoria, Australia ${ }^{2}$ Centre d'Etudes Biologique de Chizé (CEBC), UMR 7372 CNRS-Université de La Rochelle, 79360 Villiers-en-Bois, France ${ }^{3}$ Littoral Environnement et Sociétés (LIENSs), UMR 7266 CNRS-Université de La Rochelle, 2 rue Olympe de Gouges, 17000 La Rochelle, France
\end{abstract}

\begin{abstract}
Individual specialisations have been suggested to improve foraging efficiency by optimising individual capacity (physiological and behavioural) and reducing intra-specific competition in exploiting prey resources. In this study, we investigated the inter- and intra-individual variation in behaviour in an opportunistic forager, the gentoo penguin Pygoscelis papua, at Kerguelen Island, southern Indian Ocean. We used complementary bio-logging and stable isotope analyses, coupled with morphometric measurements, to: (1) determine the inter-individual variation in morphology and foraging behaviour; (2) quantify intra-individual variation in foraging behaviour; (3) investigate the links between consistency in foraging, distances travelled and body condition; and (4) determine if dietary specialisations exist and are maintained outside the breeding season. We show that this species exhibits a large inter-individual variation in foraging behaviour, with some individuals conducting very short trips close to the colony while others travelled considerably farther. Heavier individuals tended to forage in more distant locations, dive deeper and perform more benthic dives. Individual specialisation in behaviour was low to moderate at the population level, yet some individuals were very consistent. The rate of travel was not influenced by consistency, and there was a lack of correlation between body condition and foraging consistency. High inter-individual variation in feeding ecology and dietary specialisations outside of a single breeding season were observed, consistent with gentoo penguins being Type 'B' generalists (i.e. generalist populations composed of individuals each consuming a different range of foods).
\end{abstract}

KEY WORDS: Behavioural consistency · Diving behaviour · Feeding ecology · Foraging behaviour · Individual specialisations $\cdot$ Pygoscelis papua $\cdot$ Stable isotopes

\section{INTRODUCTION}

According to the optimal foraging theory, individuals implement feeding strategies aimed at maximizing energetic gains while minimizing costs (Stephens \& Krebs 1986). Individual specialisations have been suggested to improve feeding efficiency by reducing intra-specific competition or allowing individuals to catch prey they can handle and digest most efficiently

*Corresponding author: elodie.camprasse@gmail.com

${ }^{\S}$ Advance View was available online July 6, 2017

${ }^{\S}$ Corrections were made after publication. For details see www.int-res.com/abstracts/meps/v578/c_p227-242/

This corrected version: September 11, 2017
(Bolnick et al. 2003, Estes et al. 2003). Food consumption rates and body condition differ among diet specialists, and these differences may reflect differences in an individual's intrinsic quality (dit Durell et al. 2001, Bolnick et al. 2003, Anderson et al. 2009, Svanbäck \& Persson 2009, Cucherousset et al. 2011). Specialisations in foraging, involving the repetition of specific behaviours to acquire food or dietary choices over time, have until recently been poorly investigated

(C) The authors 2017. Open Access under Creative Commons by Attribution Licence. Use, distribution and reproduction are unrestricted. Authors and original publication must be credited.

Publisher: Inter-Research · www.int-res.com 
(Bolnick et al. 2003, Estes et al. 2003, Cook et al. 2006). Individual specialists have been defined as 'individuals whose niche is substantially narrower than their population's niche for reasons not attributable to their sex, age or discrete morphological group' (Bolnick et al. 2003, p. 3). Even populations usually thought to be generalists can actually be composed of individual specialists, referred to as Type 'B' generalists (individuals each specialising on a different but narrow range of food types) as opposed to Type ' $\mathrm{A}$ ' generalists (individuals all taking a wide range of food types) (Araújo et al. 2011, Loxdale et al. 2011, Layman \& Allgeier 2012, Fodrie et al. 2015).

Information on individual specialisations is crucial, as they may have significant ecological consequences at the individual and population levels, and may impact ecological processes and foraging dynamics (Bolnick et al. 2003, Matich et al. 2011, Ceia \& Ramos 2015). Thus, it is of importance to identify the mechanisms generating inter-individual variation and study the wider implications of variation in foraging behaviour to understand trophic relationships be. tween the animals and their environment (Bolnick et al. 2003, Baylis et al. 2015, Ceia \& Ramos 2015, Kernaléguen et al. 2015). The study of individual specialisations requires longitudinal sampling, in which the same individuals are sampled over time (Bolnick et al. 2003, Araújo et al. 2011). Ideally, the use of complementary techniques that represent different timescales and resolutions should be implemented to accurately describe individual specialisations and their persistence (Kernaléguen et al. 2016). Seabirds are suitable models to study individual specialisations, as most species nest in large colonies that allow for easy access to individuals that use the same environment, are strongly constrained during breeding as central place foragers and may compete for the same resources (Ratcliffe et al. 2013).

Gentoo penguins Pygoscelis papua are among the most widespread penguin species, distributed from the northern subantarctic islands (Crozet; $46^{\circ} \mathrm{S}$ ) to the Antarctic Peninsula (62 to $69^{\circ} \mathrm{S}$; Williams 1995). These birds are considered inshore opportunistic foragers, consuming both benthic and pelagic species, and exhibiting high plasticity in their diet, marine habitat use and dive behaviour (Bost \& Jouventin 1990, Woehler 1995, Lescroël \& Bost 2005, Miller et al. 2009). They consume patchy prey encompassing a large size range, from small crustaceans to large fish species (Hindell 1989, Robinson \& Hindell 1996). Accordingly, their diets vary substantially among breeding locations, within colonies and also within individuals of the same colony (Croxall et al. 1988,
Bost \& Jouventin 1990, Robinson \& Hindell 1996, Lescroël et al. 2004, Polito et al. 2015).

As gentoo penguins are long-lived and sedentary (Williams \& Rodwell 1992), individuals are expected to learn to apply efficient foraging tactics throughout their lifetime and, thus, increase their individual efficiency when foraging under situations of competition or food limitation (Estes et al. 2003). Indeed, recent studies suggest that individuals exhibit some degree of prey selection and specialisation, as judged by stomach content analysis and stable isotope values (Polito et al. 2015). However, there is little information on individual consistency in foraging behaviour and on whether such specialisations are linked to diet in this species.

In the present study, we investigated inter- and intra-individual variation in the foraging ecology of gentoo penguins. We used complementary bio-logging and stable isotope analysis, coupled with morphometric measurements to: (1) describe their inter-individual variation in morphology, spatial use and dive behaviour; (2) quantify their intra-individual variation in foraging behaviour; (3) investigate the links between consistency in foraging behaviour, distances travelled and body condition; and (4) describe their interindividual variation in feeding ecology, and determine if dietary specialisations exist and are maintained outside of the breeding season. We predicted that: (1) individuals would differ greatly in foraging metrics, as gentoo penguin diet and behaviour are known to vary among colonies and between individuals of the same colonies, and that such variation would be attributed to differences in body mass, which influences dive depth (Lescroël et al. 2004, Lescroël \& Bost 2005, Cook et al. 2013, Polito et al. 2015, Camprasse et al. 2017); (2) dietary and behavioural consistency would be detected, as populations usually considered generalists are increasingly shown to be composed of individual specialists (Woo et al. 2008, Araújo et al. 2011, Loxdale et al. 2011, Layman \& Allgeier 2012, Fodrie et al. 2015); and (3) individuals displaying higher consistency in foraging behaviour would travel shorter distances and have higher body condition, as such consistency is thought to allow individuals to forage more efficiently (Bolnick et al. 2003, Estes et al. 2003).

\section{MATERIALS AND METHODS}

\section{Study site and instrumentation}

The study was performed at Kerguelen Island in the southern Indian Ocean, one of the major breed- 
Fig. 1. One track per gentoo penguin Pygoscelis papua instrumented at Pointe Suzanne (left panel) and Estacade (right panel), Kerguelen Islands, Indian Ocean, during the crèche period in December 2014 to January 2015

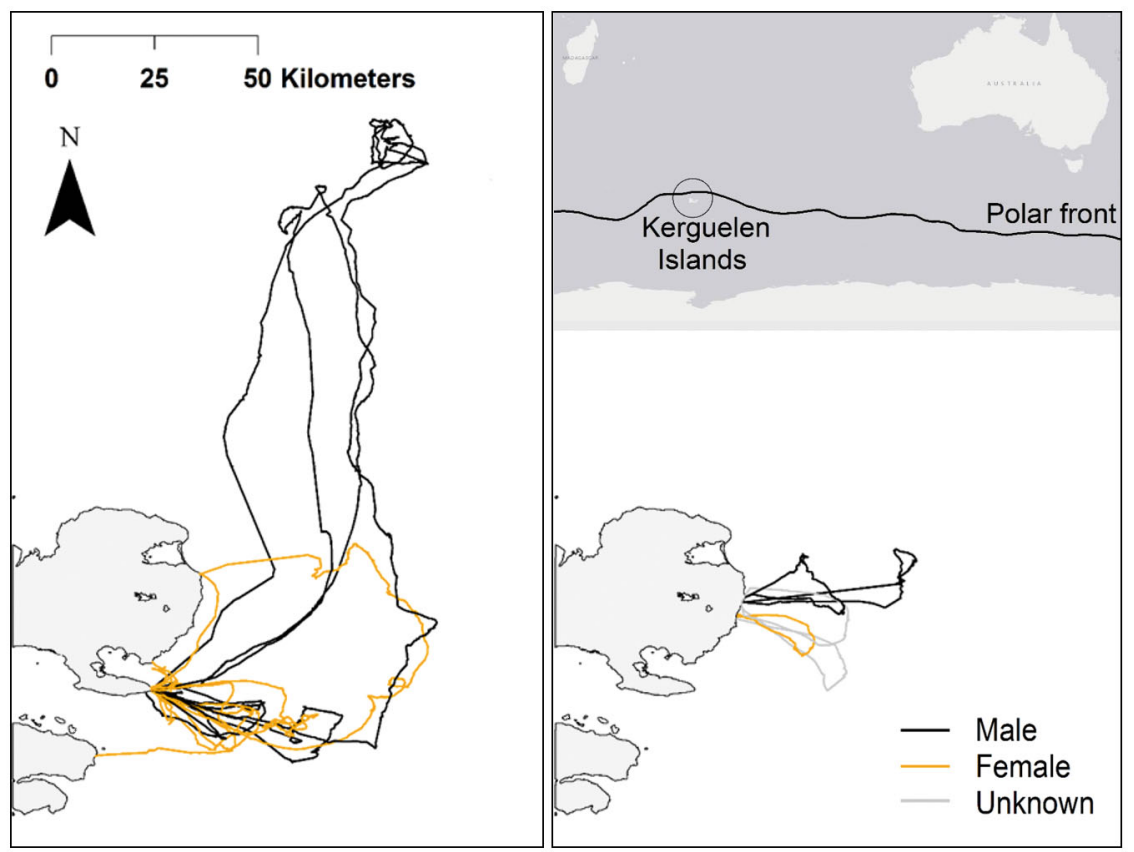

ing grounds for gentoo penguins (hereafter referred to as gentoos) with 40000 pairs (Lescroël et al. 2004, Lynch 2013). Gentoos breed along most of the Kerguelen coastline in many small to medium-sized colonies ranging from 15 to $>400$ pairs). As the diet and foraging behaviour of this species are known to vary substantially among colonies and within breeding locations, especially on Kerguelen Island (Lescroël et al. 2004, Lescroël \& Bost 2005), 2 colonies were selected to ensure that the patterns observed were not solely dependent upon colony location. Accordingly, field work was conducted at the Pointe Suzanne and Estacade colonies (ca. $20 \mathrm{~km}$ apart, $49^{\circ} 26^{\prime} \mathrm{S}, 70^{\circ} 26^{\prime} \mathrm{E}$ and $49^{\circ} 15^{\prime} \mathrm{S}, 70^{\circ} 33^{\prime} \mathrm{E}$, respectively, with ca. 50 and 25 chicks, respectively; Fig. 1). Both colonies face the open ocean. The Pointe Suzanne colony, however, faces a wider range of foraging habitats due to its proximity to a more sheltered bay (Baie Norvégienne). The Estacade colony is localized westward of the Polar Front, a productive frontal zone, on the eastward side of the Kerguelen shelf. Gentoos were in the late chick-rearing (i.e. crèche) stage at both study sites. Logistical constraints prevented sampling other colonies, as well as greater sample sizes, and so our results on site effects must be interpreted with caution.

We deployed data loggers on breeding gentoos during the late chick-rearing period (crèche stage: chicks $>4-5$ wk old), in the 2014/15 breeding season (Table 1). To determine the at-sea movements and diving behaviour of the penguins, we used Fastloc
GPS loggers (F2G 134A; FastLoc ${ }^{\circledR}$; Sirtrack; $69 \times 28 \times$ $21 \mathrm{~mm}, 39 \mathrm{~g}$ in air), alone or in combination with time-depth recorders (TDR, LAT1800S, Lotek Wireless; $36 \times 11 \times 7.2 \mathrm{~mm}, 4.8 \mathrm{~g}$ in air). GPS loggers were programmed to sample position every $5 \mathrm{~min}$. The TDR units were set to record depth and temperature at $1 \mathrm{~s}$ intervals. All attached devices, alone or in combination, weighed $<1 \%$ body mass.

At Pointe Suzanne, sampling occurred between 24 November and 9 December 2014. In total, 24 birds were instrumented for 4 to $16 \mathrm{~d}$ according to the possibilities of recapture. We used either 2 kinds of instruments (GPS+TDR: $\mathrm{n}=18$ ), or only 1 instrument (GPS: $\mathrm{n}=4$, TDR: $\mathrm{n}=2$ ). At Estacade, 9 birds were instrumented between 20 December 2014 and 4 January 2015 with GPS+TDR for 4 to $15 \mathrm{~d}$.

All instrumented birds were confirmed breeders, with only birds that were observed feeding chicks being sampled. Individuals were weighed in a cloth bag using a suspension scale $( \pm 25 \mathrm{~g}$, Pesola) before data loggers were attached to the dorsal feathers using waterproof tape (Tesa 4651) and cyanoacrylate glue (Loctite 401 Instant Adhesive). Individuals were then released and resumed normal behaviours. With the exception of 3 individuals from Estacade that were recaptured on the beach a few kilometres north or south of the colony, all birds were recaptured at the colony after several foraging trips. The data loggers were removed and individuals were weighed again. Measurements of bill length and depth were taken with Vernier callipers $( \pm 0.05 \mathrm{~mm})$ and flipper length with a 
Table 1. Summary of bio-logging deployments for gentoo penguins Pygoscelis papua instrumented and retrieved at Pointe Suzanne and Estacade (Kerguelen Islands, Indian Ocean) during the crèche period in December 2014 to January 2015; F: female, M: male, -: missing data

\begin{tabular}{|c|c|c|c|c|c|c|c|c|}
\hline Bird & Sex & $\begin{array}{c}\text { Body } \\
\text { condition } \\
\text { index }\end{array}$ & $\begin{array}{c}\text { Initial } \\
\text { mass } \\
(\mathrm{kg})\end{array}$ & $\begin{array}{c}\text { Bill } \\
\text { depth } \\
(\mathrm{mm})\end{array}$ & $\begin{array}{c}\text { Bill } \\
\text { length } \\
(\mathrm{mm})\end{array}$ & $\begin{array}{c}\text { Flipper } \\
\text { length } \\
(\mathrm{mm})\end{array}$ & $\begin{array}{l}\text { Tracking } \\
\text { time } \\
\text { (d) }\end{array}$ & $\begin{array}{c}\text { Total } \\
\text { no. of } \\
\text { trips }\end{array}$ \\
\hline \multicolumn{9}{|c|}{ Pointe Suzanne } \\
\hline 4 & F & 0.4 & 5.0 & 13.4 & 81.0 & 225.0 & 8.3 & 15 \\
\hline 7 & F & -0.4 & 5.8 & 16 & 95.0 & 244.0 & 6.9 & 4 \\
\hline 9 & F & -0.4 & 3.6 & 13.3 & 76.0 & 215.0 & 10.9 & 11 \\
\hline 10 & F & -0.4 & 4.4 & 15.6 & 81.0 & 220.0 & 7.0 & 9 \\
\hline 13 & F & -0.4 & 4.4 & 15.8 & 80.0 & 221.0 & 10 & 3 \\
\hline 15 & $\mathrm{~F}$ & -0.3 & 5.2 & 15.1 & 88.0 & 232.0 & 4.0 & 3 \\
\hline 20 & F & 0.2 & 5.0 & 14.9 & 75.0 & 230.0 & 4.5 & 3 \\
\hline 22 & F & 0.0 & 4.5 & 15.5 & 81.0 & 210.0 & 13.3 & 6 \\
\hline 24 & $\mathrm{~F}$ & 0.4 & 5.1 & 14.3 & 84.0 & 220.0 & 4.4 & 3 \\
\hline 1 & M & -1.7 & 4.3 & 16.7 & 95.0 & 234.0 & 6.5 & 9 \\
\hline 2 & M & - & 5.9 & 11.8 & - & 235.0 & 8.2 & 12 \\
\hline 3 & M & 0.4 & 6.8 & 18.1 & 91.0 & 245.0 & 7.9 & 2 \\
\hline 5 & M & - & 6.1 & 16.5 & - & 235.0 & 6.1 & 3 \\
\hline 6 & M & 0.4 & 5.9 & 18.4 & 79.0 & 231.0 & - & - \\
\hline 11 & M & -0.1 & 5.8 & 16.5 & 89.0 & 238.0 & 8.7 & 3 \\
\hline 12 & M & 0.3 & 5.7 & 17.6 & 85.0 & 225.0 & 8.0 & 2 \\
\hline 14 & $\mathrm{M}$ & -0.2 & 5.3 & 16.5 & 90.0 & 228.0 & 4.4 & 4 \\
\hline 17 & M & -0.1 & 5.3 & 16.8 & 85.0 & 230.0 & 5.4 & 3 \\
\hline 19 & M & -0.2 & 5.7 & 18.2 & 89.0 & 232.0 & - & - \\
\hline 23 & M & -0.3 & 5.8 & 17.3 & 95.0 & 232.0 & - & - \\
\hline \multicolumn{9}{|c|}{ Estacade } \\
\hline 26 & - & - & 4.5 & - & - & - & 6.1 & 2 \\
\hline 28 & - & - & 6.4 & - & - & - & 15.4 & 3 \\
\hline 27 & $\mathrm{~F}$ & - & 5 & 17.1 & 82.0 & 220.0 & 4.0 & 3 \\
\hline 25 & M & - & 6.6 & - & 91.0 & 234.0 & 5.9 & 2 \\
\hline 30 & M & 1.4 & 7.8 & 19.5 & 92.0 & 235.0 & 6.2 & 6 \\
\hline 33 & M & 1.1 & 6.3 & 16.4 & 85.0 & 224.0 & - & - \\
\hline
\end{tabular}

while their $\delta^{15} \mathrm{~N}$ values increase with trophic level (Cherel et al. 2010). Isotopic values were measured on whole blood and feathers. The rationale is that the 2 complementary tissues integrate different periods of information, due to the fact that the keratin in feathers is inert after synthesis (details in Cherel et al. 2008). Blood is a metabolic active tissue that integrates a period of weeks before sampling, whereas feathers reflect the diet at the time they were grown, as feathers are metabolically inert after they are grown (Cherel et al. 2000). In the present study, blood isotopic values integrated a few weeks before sampling, thus corresponding to the breeding period (Bearhop et al. 2006). In contrast, gentoos moult once a year, at the end of the breeding period, after a period of $10 \mathrm{~d}$ at sea dedicated to replenishment of body reserves (Croxall \& Davis 1999, Polito et al. 2011). They then fast ashore for about 3 wk, using their body reserves to cover the energetic and nutrient needs for moulting and fasting (Croxall \& Davis 1999). Hence, the isotopic values of feathers document the foraging ecology of penguins during the pre-moult period of hyperphagia at sea during which they build up metal ruler $( \pm 1 \mathrm{~mm})$. In addition, a blood sample $(0.5-1.5 \mathrm{ml})$ was obtained by venipuncture of a tarsal vein for stable isotope analysis and molecular sex determination. Feathers $(n=3-6)$ were plucked from the thorax region for stable isotope analysis. Handling times ranged from 15 to $20 \mathrm{~min}$, during which the bird's head was covered with a hood to reduce stress. Of the 33 birds instrumented at the 2 study sites, 28 birds were recaptured, of which 4 did not go to sea to forage and 2 individuals had TDRs that malfunctioned. Overall, 22 individuals provided data which were analysed (Pointe Suzanne: $\mathrm{n}=17$, Estacade: $\mathrm{n}=5$ ). All 22 individuals conducted more than 1 trip, with 19 providing both TDR and GPS data.

\section{Isotopic analyses}

The $\delta^{13} \mathrm{C}$ values of seabirds reflect their foraging habitats (Cherel \& Hobson 2007, Jaeger et al. 2010), energy reserves (Cherel et al. 2008), here almost $1 \mathrm{yr}$ before sampling the instrumented gentoos.

In the laboratory, blood samples were freeze-dried and powdered. Lipid extraction was unnecessary, as the C:N mass ratio was $<3.5$ for all blood samples (Cherel et al. 2005b); C:N mass ratios $\pm \mathrm{SD}$ were $3.29 \pm 0.06$ (whole blood, $\mathrm{n}=25$ ) and $3.17 \pm 0.05$ (feathers, $\mathrm{n}=27$ ). A pool of 3 feathers bird ${ }^{-1}$ was cleaned of surface lipids and contaminants using a 2:1 chloroform:methanol bath, air-dried and cut into small pieces. For each feather, the rachis and the top $5 \mathrm{~mm}$ of the feather synthesised at sea were discarded before analysis so that the remaining feather sections were homogeneous and corresponded to the fasting period (Cherel et al. 2005a).

Nitrogen and carbon isotopic ratios were measured on aliquots of 0.2 to $0.4 \mathrm{mg}$ with a continuous-flow isotope-ratio mass spectrometer (Thermo Scientific Delta V Advantage) coupled to an elemental analyser (Thermo Scientific Flash EA 1112). Results are 
presented in the usual $\delta$ notation relative to Vienna PeeDee Belemnite (VPDB) for carbon and atmospheric $\mathrm{N}_{2}$ (AIR) for nitrogen. Replicate measurements of internal laboratory standards (acetanilide and peptone) indicated measurement errors $<0.15 \%$ for both $\delta^{13} \mathrm{C}$ and $\delta^{15} \mathrm{~N}$. Blood and/or feather sampling was not possible on all individuals instrumented, resulting in the collection of either no samples, only feathers, only blood, or both samples for each individual. Stable isotope values were obtained from 25 individuals for blood (11 females, 14 males), and 27 individuals for feathers (11 females, 13 males, 3 unknown). Both tissues were sampled in 24 individuals (11 females, 13 males). Of these 24 individuals, 16 also had both GPS and TDR data, 1 had TDR data only, 3 had GPS data only, and 4 did not have any bio-logging data.

\section{Data processing}

All data analyses were conducted in the R Statistical Environment in version 3.3 (R Core Team 2015). The GPS records for each bird were visually inspected to identify individual foraging trips. As some birds hauled out in some locations distant from the colony for a few hours to several days, foraging trips were defined as the time between when an individual left a land-based position until it came back ashore. The diveMove package (Luque 2007) was used to apply a speed filter to the GPS data to remove erroneous locations (with a speed threshold of $1.5 \mathrm{~m}$ $\mathrm{s}^{-1}$ based on the $95^{\text {th }}$ percentile of swim speeds for all individuals). The GPS records were interpolated to $1 \mathrm{~s}$ intervals in the adehabitatLT package (Calenge 2015) to provide spatial information for the dive records. Furthermore, the packages trip (Sumner 2009) and $s p$ (Pebesma \& Bivand 2005) were used to obtain summaries of at-sea movements and investigate the consistency in habitat use. Individual tracks were overlaid with a grid comprised of $2 \times 2 \mathrm{~km}$ cells, where the number of grid cells used were calculated for each trip. Means and coefficients of variation for each individual were calculated for trip duration, maximum range, and horizontal distance travelled per trip and per hour. Bearing for each trip was calculated as the angle between the colony and the most distal point of the tracks, and standard deviation in bearing was calculated for each individual using the circular package (Agostinelli \& Lund 2011).

The diveMove package was used to obtain summaries of diving metrics from TDR records (only dives deeper than $2 \mathrm{~m}$ were considered to be forag- ing dives, following Lescroël \& Bost 2005). The lubridate package (Grolemund \& Wickham 2011) was used to identify night and day dives based on sunset and sunrise times at the relevant sites. Benthic and pelagic dives were determined based on the proportion of dive time that was spent in the bottom phase for each dive (phase detected by the 'diveStats' function after descent and before ascent), and the depth achieved on consecutive dives. If the dive depth stayed within $5 \%$ of the maximum depth for this dive for more than $15 \mathrm{~s}$, and if the dive was within $5 \%$ of the maximum depth achieved during the last $15 \mathrm{~min}$ of diving, the dive was labelled as 'flat-benthic'. If the dive was within $5 \%$ of the maximum depth achieved for 'flat-benthic' dives during the last 15 min of diving, but the other criterion was not met, the dive was labelled as 'V-benthic'. If the dive met neither of these criteria, the dive was labelled as 'pelagic'. The proportion of pelagic dives was then determined. Means and standard deviations per trip were calculated for bottom time and mean bottom depth of each dive, the total vertical distance travelled per trip and per hour, and the proportion of pelagic and night diving. Horizontal and vertical distances travelled were summed to provide an index of foraging energy expenditure per trip and per hour (Wilson et al. 1986).

An index of consistency in habitat use was calculated for each animal. For each trip, the number of grid cells used by the individuals was identified. The number of shared grid cells between each pair of trips (e.g. trip 1 and trip 2, trip 2 and trip 3, trip 1 and trip 3 etc.) was determined and the average of these calculated. This number was then divided by the average number of grid cells used per trip. Different grid cell sizes were tested to calculate the index of consistency in habitat use (from $1 \times 1 \mathrm{~km}$ to $10 \times 10 \mathrm{~km}$ ) to check the influence of grid cell size on our estimate of spatial consistency. Indices obtained, regardless of cell grid sizes, were highly correlated, and data from the $2 \times 2 \mathrm{~km}$ grid cell size are presented.

\section{Statistical analyses}

Body mass and morphometric measurements were correlated (linear regressions: beak depth: $F_{1,18}=$ 14.62, $\mathrm{R}^{2}=0.42, \mathrm{p}=0.001$; flipper length: $F_{1,18}=14.15$, $\mathrm{R}^{2}=0.65, \mathrm{p}=0.001$ ) and therefore, only relationships with body mass were further investigated in models. A principal component analysis was run on flipper and bill length and bill depth with the FactoMineR package (Lê et al. 2008). Residuals from a linear regression of the first principal component against body 
mass were then used as an index of body condition (Cuervo et al. 2009). The first principal component of the morphometric measurements explained $72.2 \%$ of the total variation and was therefore used as an estimate of structural size. There was no significant difference between the sexes in the slopes or elevations of the linear regressions of body mass on this estimate of structural size. Therefore, data were pooled to estimate individual body condition.

The following spatial metrics were highly correlated: trip duration and maximum range (linear mixed effects models: $\left.F_{1,17}=61.17, \mathrm{R}^{2}=0.78, \mathrm{p}<0.001\right)$; and maximum range and total distance travelled (linear mixed effects models: $F_{1,17}=285.7, \mathrm{R}^{2}=0.94, \mathrm{p}<$ 0.001). Consequently, only maximum range was used in linear mixed effects models. Similarly, the following diving metrics were highly correlated: bottom depth and total vertical distance travelled (linear mixed effects models: $F_{1,17}=41.41, \mathrm{R}^{2}=0.69, \mathrm{p}<$ 0.001 ); and dive time and bottom depth (linear mixed effects models: $F_{1,17}=91.04, \mathrm{R}^{2}=0.83, \mathrm{p}<0.001$ ). Thus, only bottom depth was included in further analyses.

Following a preliminary analysis to remove outliers, we used linear regressions, and linear mixed effects models in the package lme4 (Bates et al. 2014) where individuals had repeated samples, to investigate relationships between morphometric measurements, consistency in foraging strategies and stable isotope values. For all models, backward-stepwise model selection was used to select the most parsimonious model (Ratcliffe et al. 2013). First, the most appropriate random effects structure was identified with the restricted maximum likelihood (REML), then the best fixed effects structure was determined using maximum likelihood (ML) after models were compared with the ANOVA function, and the most parsimonious models were found based on their Akaike's Information Criteria. For models in which 1 observation per trip was used (i.e. for spatial use metrics), individuals were included in the random effects. For models in which multiple observations per trip were used (i.e. for diving behaviour metrics), trip nested within individuals was included in the random effects. The selected models were refitted with REML to estimate the model parameters (Zuur et al. 2009). The residuals of the models were inspected, and whenever there was evidence of heterogeneity in the residuals, a sex- and/or site-specific variance structure was applied (Zuur et al. 2009).

More specifically, in order to describe the interindividual variation in morphology and foraging behaviour, we investigated the effects of sex and stage on morphometric measurements, and the effects of sex, site and body mass on foraging metrics (interactions between fixed effects could not be investigated due to small sample sizes). A $k$-means clustering analysis was performed to determine whether individuals clustered according to their foraging behaviour. In order to quantify the intra-individual variation in diving behaviour and spatial use, we used the $\mathrm{R}$ package ape (Paradis et al. 2004) to perform a variance component analysis. This method calculates the variance, standard deviation and proportion of total variance occurring at the levels of individual, and trip within individual when multiple observations per trip were obtained, as well as the residual variation (Ratcliffe et al. 2013, Harris et al. 2014). An estimate of individual specialisation is given by the proportion of variance explained by the individual variance component (Bolnick et al. 2003, Dingemanse \& Dochtermann 2013, Ratcliffe et al. 2013). When models including sex, site or body mass were better than the equivalent models without fixed effects (i.e. null models), the variance component analysis was run on both null and optimal models to quantify the reduction in variance explained by the individual, or the trip effects after the inclusion of the fixed effects (Ratcliffe et al. 2013). In order to investigate the links between consistency in foraging behaviour, vertical and horizontal distances travelled, and body condition, linear regressions were used. In order to quantify the inter-individual variation in trophic niche and foraging behaviour, and determine if dietary specialisations were maintained outside of a single breeding season, relationships between carbon and nitrogen values in blood and feathers, respectively, were investigated. Results presented are means $\pm \mathrm{SD}$, unless stated otherwise.

\section{RESULTS}

\section{Inter-individual variation in morphometry and at-sea behaviour}

Gentoo penguins varied considerably in their body condition, mass and morphometric measurements (Tables 1 \& 2). Body condition indices were lower at Pointe Suzanne (linear regression: $F_{1,18}=14.42, \mathrm{R}^{2}=$ $0.4, \mathrm{p}=0.001)$ compared to Estacade but similar between sexes (linear regression: $F_{1,18}=0.37, \mathrm{R}^{2}=$ $-0.03, \mathrm{p}=0.5$ ). Lastly, females had smaller bill lengths than males (linear regression: $F_{1,18}=32.68$, $\mathrm{R}^{2}=0.63, \mathrm{p}<0.001$ ), as well as flipper lengths (linear regression: $F_{1,18}=4.96, \mathrm{R}^{2}=0.2, \mathrm{p}=0.04$ ). 
Table 2. Summary of morphometric measurements for gentoo penguins Pygoscelis papua instrumented and retrieved at Pointe Suzanne and Estacade (Kerguelen Islands, Indian Ocean) during the crèche period in December 2014 to January 2015; F: female, M: male

\begin{tabular}{|clrrr|}
\hline & & Mean \pm SD & Minimum & Maximum \\
\hline Body condition & Pointe Suzanne & $-0.1 \pm 0.5$ & -1.7 & 0.4 \\
index & Estacade & $1.3 \pm 0.2$ & 1.1 & 1.4 \\
& F & $-0.1 \pm 0.4$ & -0.4 & 0.4 \\
& M & $0.1 \pm 0.8$ & -1.7 & 1.4 \\
Body mass (kg) & Pointe Suzanne & $5.2 \pm 0.8$ & 3.7 & 6.8 \\
& Estacade & $7.1 \pm 1.0$ & 6.4 & 7.8 \\
& F & $4.8 \pm 0.6$ & 3.7 & 5.8 \\
& M & $5.9 \pm 0.9$ & 4.3 & 7.8 \\
Bill depth (mm) & Pointe Suzanne & $16.1 \pm 1.5$ & 13.3 & 18.4 \\
& Estacade & $18.0 \pm 2.2$ & 16.4 & 19.5 \\
& F & $14.9 \pm 1.0$ & 13.3 & 16.0 \\
& M & $17.5 \pm 1.0$ & 16.4 & 19.5 \\
Bill length (mm) & Pointe Suzanne & $85.5 \pm 6.3$ & 75.0 & 95.0 \\
& Estacade & $88.5 \pm 4.9$ & 85.0 & 92.0 \\
& F & $82.3 \pm 6.1$ & 75.0 & 95.0 \\
& M & $88.7 \pm 4.7$ & 79.4 & 95.0 \\
Flipper length & Pointe Suzanne & $228.4 \pm 9.2$ & 210.0 & 245.0 \\
& Estacade & $229.0 \pm 7.8$ & 224.0 & 235.0 \\
& F & $224.1 \pm 10.1$ & 210.0 & 244.0 \\
& M & $232.2 \pm 5.9$ & 224.0 & 245.0 \\
\hline
\end{tabular}

means clustering analysis revealed 3 different foraging strategies: birds that travelled farther, dived deeper and were less pelagic $(n=5$, means $\pm S E$ : $49.3 \pm 19.3 \mathrm{~km}, 40.2 \pm 15.8 \mathrm{~m}, 70.9 \pm$ $11.4 \%$, respectively); birds that stayed close to colony had the shallowest dives and displayed the highest percentage of pelagic diving $(\mathrm{n}=8$, means \pm SE: $8.1 \pm 4.6 \mathrm{~km}, 13.6 \pm 7.1 \mathrm{~m}$, $89.7 \pm 6.9 \%$, respectively); and birds with intermediate foraging metrics $(\mathrm{n}=6$, means \pm SE: $22.0 \pm 5.0 \mathrm{~km}, 30.7$ $\pm 5.4 \mathrm{~m}, 73.7 \pm 10.2 \%$, respectively). Both sexes and sites were represented in each cluster. Lastly, sex and site did not influence spatial metrics (Table 4).

There was also considerable interindividual variation in the diving behaviour of the instrumented birds, irrespective of colony. Some individuals performed very short and shallow dives and travelled short vertical distances,
Overall, a total of 113 foraging trips were obtained (16 from Estacade, 97 from Pointe Suzanne) with 2 to 15 trips recorded per individual (mean $=5$ ) lasting 4.0 to $15.4 \mathrm{~d}$ each $($ mean $=7.3$; Table 1$)$. Individuals varied considerably in their spatial use of the marine environment (Table 3), even within the same colony, with some individuals foraging close to the shore, while others travelled towards the continental shelf. Individual maximum distances from the colony averaged $21.6 \pm 18.7$ (3.3-78.3) km, trip durations averaged $26.6 \pm 22.8(5.1-77.6) \mathrm{h}$, total horizontal distances covered averaged $65.0 \pm 56.7(9.9-217.4) \mathrm{km}$, and horizontal distances per hour averaged $2.7 \pm 0.5(1.8-3.7) \mathrm{km}$. Furthermore, individual birds exploited different areas around the colony (Fig. 1). Six birds hauled out in locations away from the colony for periods of 10 to $57 \mathrm{~h}$. Birds did not go on 2 consecutive long trips, but rather tended to alternate long and short trips. A $k$ -
Table 3. Summary of spatial use metrics for gentoo penguins Pygoscelis papua instrumented and retrieved at Pointe Suzanne and Estacade (Kerguelen Islands, Indian Ocean) during the crèche period in December 2014 to January 2015 (values are means $\pm \mathrm{SD}$ ); F: female, M: male

\begin{tabular}{|lcccccc|}
\hline Bird & Sex & $\begin{array}{c}\text { Mean } \\
\text { bearing } \\
\left({ }^{\circ}\right)\end{array}$ & $\begin{array}{c}\text { Trip } \\
\text { duration } \\
(\mathrm{h})\end{array}$ & $\begin{array}{c}\text { Maximum } \\
\text { range } \\
(\mathrm{km})\end{array}$ & $\begin{array}{c}\text { Total hori- } \\
\text { zontal dis- } \\
\text { tance }(\mathrm{km})\end{array}$ & $\begin{array}{c}\text { Horizontal } \\
\text { distance } \\
\mathrm{h}^{-1}(\mathrm{~km})\end{array}$ \\
\hline \multicolumn{7}{c}{ Pointe Suzanne } \\
4 & $\mathrm{~F}$ & $98.8 \pm 0.6$ & $6.6 \pm 5.1$ & $3.3 \pm 1.7$ & $9.9 \pm 5.8$ & $1.8 \pm 0.8$ \\
7 & $\mathrm{~F}$ & $116.9 \pm 0.3$ & $26.4 \pm 25.7$ & $17.2 \pm 10.8$ & $54.3 \pm 43.1$ & $2.9 \pm 1.2$ \\
9 & $\mathrm{~F}$ & $55.5 \pm 1.1$ & $5.1 \pm 3.1$ & $4.0 \pm 1.0$ & $11.0 \pm 6.0$ & $2.3 \pm 0.6$ \\
10 & $\mathrm{~F}$ & $129.9 \pm 0.2$ & $7.9 \pm 4.5$ & $5.7 \pm 2.1$ & $17.5 \pm 8.6$ & $2.4 \pm 0.5$ \\
13 & $\mathrm{~F}$ & $11.5 \pm 1.5$ & $66.0 \pm 61.7$ & $39.4 \pm 18.7$ & $133.8 \pm 98.7$ & $2.5 \pm 0.8$ \\
15 & $\mathrm{~F}$ & $127.5 \pm 0.2$ & $11.5 \pm 7.5$ & $13.9 \pm 3.4$ & $35.0 \pm 16.7$ & $3.3 \pm 0.6$ \\
20 & $\mathrm{~F}$ & $127.0 \pm 0.1$ & $8.2 \pm 8.3$ & $10.0 \pm 8.9$ & $24.9 \pm 25.3$ & $3.0 \pm 0.1$ \\
22 & $\mathrm{~F}$ & $90.4 \pm 0.4$ & $33.8 \pm 35.4$ & $17.4 \pm 15.4$ & $72.4 \pm 70.2$ & $2.2 \pm 0.4$ \\
24 & $\mathrm{~F}$ & $162.2 \pm 0.0$ & $14.6 \pm 7.4$ & $9.9 \pm 1.5$ & $29.3 \pm 8.6$ & $2.3 \pm 0.8$ \\
1 & $\mathrm{M}$ & $106.0 \pm 0.4$ & $4.8 \pm 3.8$ & $4.7 \pm 2.8$ & $10.9 \pm 6.2$ & $2.6 \pm 1.0$ \\
2 & $\mathrm{M}$ & $66.3 \pm 0.5$ & $8.5 \pm 5.7$ & $7.7 \pm 4.6$ & $22.4 \pm 15.1$ & $2.9 \pm 0.6$ \\
3 & $\mathrm{M}$ & $56.3 \pm 0.8$ & $77.6 \pm 43.7$ & $78.3 \pm 62.8$ & $217.4 \pm 187.3$ & $2.5 \pm 1.0$ \\
5 & $\mathrm{M}$ & $125.2 \pm 0.1$ & $20.2 \pm 16.5$ & $25.4 \pm 10.8$ & $67.1 \pm 41.3$ & $3.7 \pm 0.7$ \\
11 & $\mathrm{M}$ & $56.4 \pm 0.5$ & $56.0 \pm 75.2$ & $59.4 \pm 70.2$ & $164.4 \pm 211.0$ & $3.2 \pm 0.4$ \\
12 & $\mathrm{M}$ & $107.0 \pm 0.1$ & $70.0 \pm 38.6$ & $32.3 \pm 3.8$ & $140.5 \pm 60.9$ & $2.1 \pm 0.3$ \\
14 & $\mathrm{M}$ & $91.2 \pm 0.1$ & $18.8 \pm 10.7$ & $21.9 \pm 10.2$ & $53.2 \pm 28.2$ & $2.9 \pm 0.3$ \\
17 & $\mathrm{M}$ & $114.4 \pm 0.1$ & $19.8 \pm 17.1$ & $17.6 \pm 12.2$ & $49.5 \pm 38.8$ & $2.5 \pm 0.4$ \\
Estacade & & & & & \\
27 & $\mathrm{~F}$ & $127.9 \pm 0.2$ & $11.1 \pm 12.8$ & $9.5 \pm 6.3$ & $23.3 \pm 16.8$ & $3.1 \pm 1.4$ \\
25 & $\mathrm{M}$ & $79.7 \pm 0.2$ & $44.8 \pm 5.3$ & $28.7 \pm 2.4$ & $89.4 \pm 2.4$ & $2.0 \pm 0.3$ \\
30 & $\mathrm{M}$ & $77.3 \pm 0.3$ & $17.9 \pm 1.0$ & $16.9 \pm 2.1$ & $48.9 \pm 3.4$ & $2.7 \pm 0.2$ \\
26 & - & $137.2 \pm 0.1$ & $12.9 \pm 7.7$ & $15.4 \pm 12.3$ & $35.1 \pm 29.0$ & $2.5 \pm 0.8$ \\
28 & - & $86.3 \pm 0.8$ & $42.9 \pm 61.0$ & $36.9 \pm 42.9$ & $120.7 \pm 164.5$ & $3.5 \pm 1.0$ \\
& & & & & &
\end{tabular}


Table 4. Model ANOVA testing the effect of gentoo penguin Pygoscelis papua sex and site on maximum range, bottom depth and repeatability, including bird as a random factor or trip nested within bird (likelihood ratio [LR] for linear mixed effects models and $F$ values for simple linear regressions). The last row reports on the linear mixed effects model testing the effect of dive depth on the proportion of pelagic dives. Values in bold are significant

\begin{tabular}{|lccccc|}
\hline Variable & Type of model & Parameters & LR/F test & df & p \\
\hline $\begin{array}{l}\text { Maximum } \\
\text { range }\end{array}$ & Linear & Random effect: bird & 33.21 & 6 & $<\mathbf{0 . 0 0 0 1}$ \\
& & Fixed effects & & & \\
& & Sex & 3.21 & 8 & 0.07 \\
Bottom & Site & 0 & 8 & 0.98 \\
depth & minear & Body mass & 3.15 & 8 & 0.08 \\
& & Random effect: bird/trip & 1236.29 & 9 & $<\mathbf{0 . 0 0 0 1}$ \\
& & Fixed effects & 3.2 & 8 & 0.07 \\
Repeatability & Linear model & Site & 0.46 & 8 & 0.5 \\
indices & & Body mass & 7.29 & 8 & $\mathbf{0 . 0 1}$ \\
Proportion of & Linear & Sex & 1.42 & 2,18 & 0.27 \\
pelagic dives & mixed effects & Site & 0.04 & 1,18 & 0.84 \\
& & Fixed effects & 84.83 & 4 & $<\mathbf{0 . 0 0 0 1}$ \\
\hline
\end{tabular}

between individuals (mean distance per trip: $96.6 \pm 81.0$ [13.3-279.6] km; mean distance per hour of foraging: $3.5 \pm 0.6[2.3-4.8] \mathrm{km})$.

Sex and site did not significantly influence dive depth (Table 4). Some individuals performed almost entirely pelagic dives while, for others, benthic dives represented up to $48 \%$ of all dives (Table 5). Furthermore, individuals varied in their diving schedule, with some individuals diving half of their time at night, and other individuals diving mostly during the day (Table 5, Fig. 2). Daylight dives were on average $30.3 \pm 37.5 \mathrm{~m}$ deep and $68.5 \pm 53.2 \mathrm{~s}$ long $(\mathrm{n}=$ $24336,75 \%$ of dives recorded)

while others dived for much longer and deeper, and travelled much greater vertical distances (Table 5). On average, individuals spent $70.9 \pm 20.1$ (29.5-106.8) s at the bottom of dives, dived to bottom depths of $26.0 \pm$ 14.7 (5.1-61.6) $\mathrm{m}$, and travelled total vertical distances of $26.6 \pm 23.2(2.1-74.5) \mathrm{km}$, and hourly vertical distances of $0.8 \pm 0.2(0.4-1.1) \mathrm{km}$. Accordingly, the distance travelled (both horizontal and vertical) varied while night dives were on average $9.2 \pm 10.2 \mathrm{~m}$ deep and $52.3 \pm 39.9 \mathrm{~s}$ long ( $\mathrm{n}=8298,25 \%$ of dives recorded). Several individuals dived at night during multiple-day trips while other birds performed short trips (ca. $10 \mathrm{~km}$ from the colony) and dived predominantly at night. The frequency of night diving increased with the proportion of pelagic diving, which averaged $76.8 \%$ during the day and $92.9 \%$ at night (Fig. 2).

Table 5. Summary of dive metrics and distances travelled for gentoo penguins Pygoscelis papua instrumented and retrieved at Pointe Suzanne and Estacade (Kerguelen Islands, Indian Ocean) during the crèche period in December 2014 to January 2015 (values are means $\pm \mathrm{SD}) ;$ F: female, M: male, -: unsexed

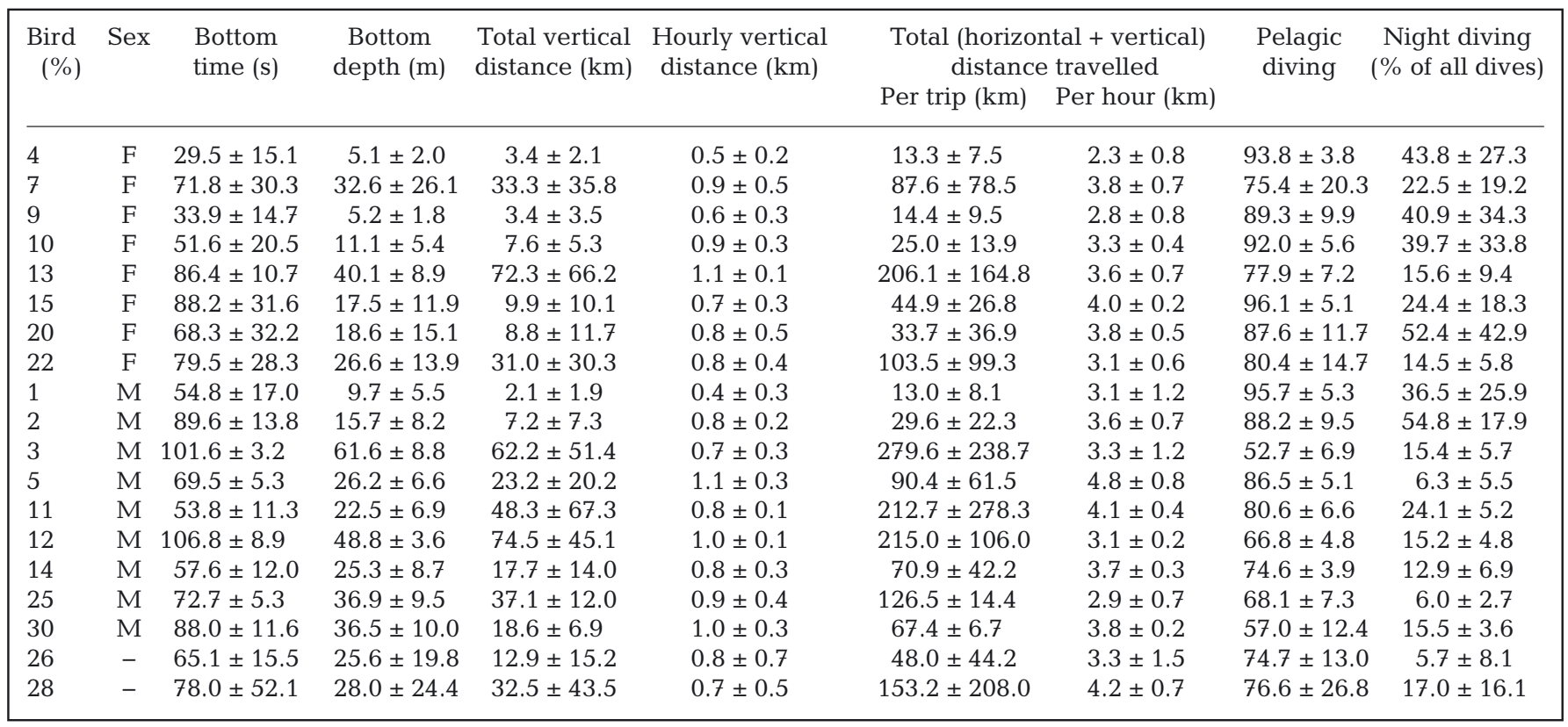




\section{(A) Temporal variation in frequency of dives}

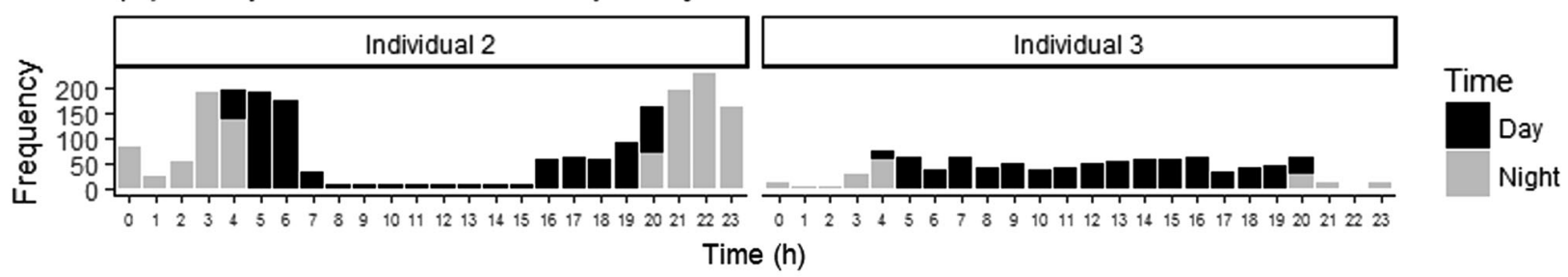

(B) Temporal variation in dive depth

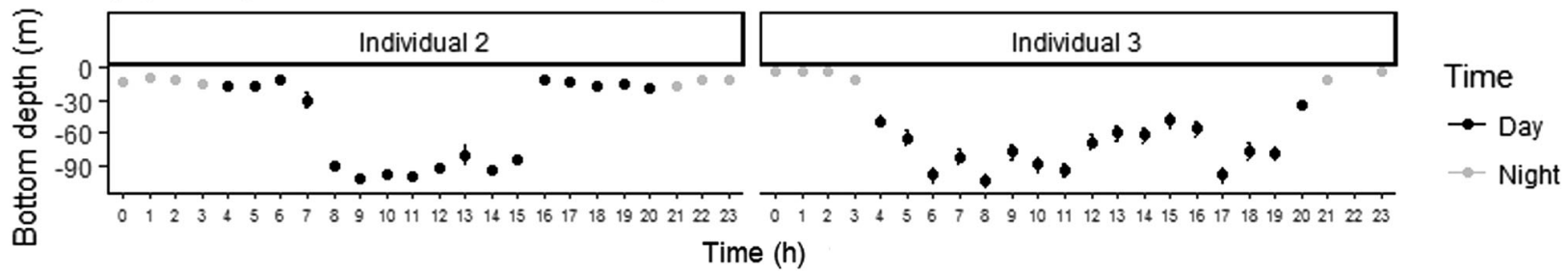

(C) Relationship between proportion of pelagic dives and the proportion of dives at night

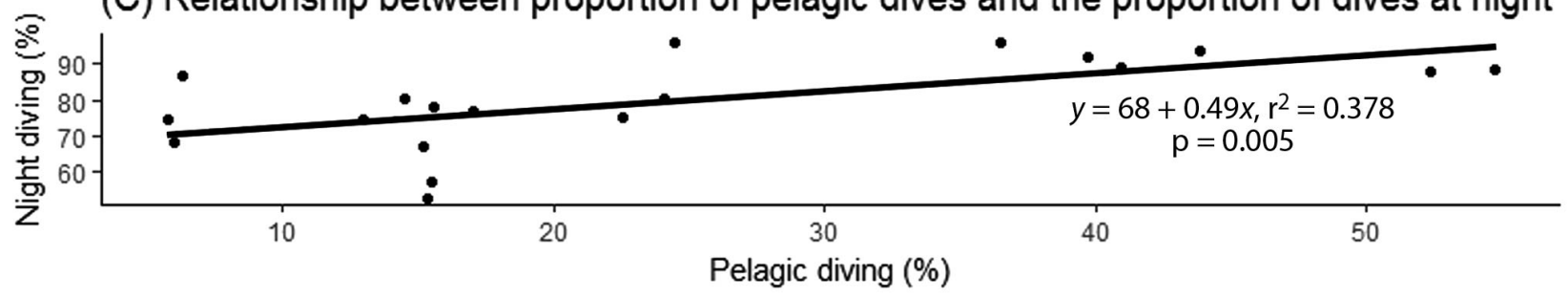

Fig. 2. (A) Frequency of night diving, (B) distribution of dive depths across time of day and (C) relationship between night and pelagic diving in gentoo penguins Pygoscelis papua (panels A and B show individuals representative of the most benthic and the most pelagic individuals) instrumented at Pointe Suzanne during the crèche period in December 2014 to January 2015

\section{Intra-individual variation and consistency in foraging behaviour}

The large differences in standard deviations between individuals indicate a substantial degree of intra-individual variation both in spatial use and dive metrics (Tables $3-5$, respectively). At the population level, the variance component analysis showed low to moderate individual specialisations both in dive behaviour and spatial use (Table 6). The indices of consistency in habitat use were not influenced by sex or site (Table 4 , mean $0.37 \pm 0.20$, range: $0.05-0.73$, Fig. 3). Some penguins were very consistent in the proportion of pelagic or benthic dives they performed (e.g. individual 14 stayed within $10 \%$ of its own values) while others varied greatly (e.g. individual 28 ranged from 47 to $98 \%$ of pelagic dives between trips; Fig. 4). The total (horizontal + vertical) distance travelled per hour was not correlated with repeatability indices (linear regression: $\left.F_{1,17}=0.97, \mathrm{R}^{2}=-0.002, \mathrm{p}=0.34\right)$. Lastly, body condition did not vary with consistency in habitat use (linear regression: $F_{1,12}=0.16, \mathrm{R}^{2}=$ $-0.07, \mathrm{p}=0.70$ ).

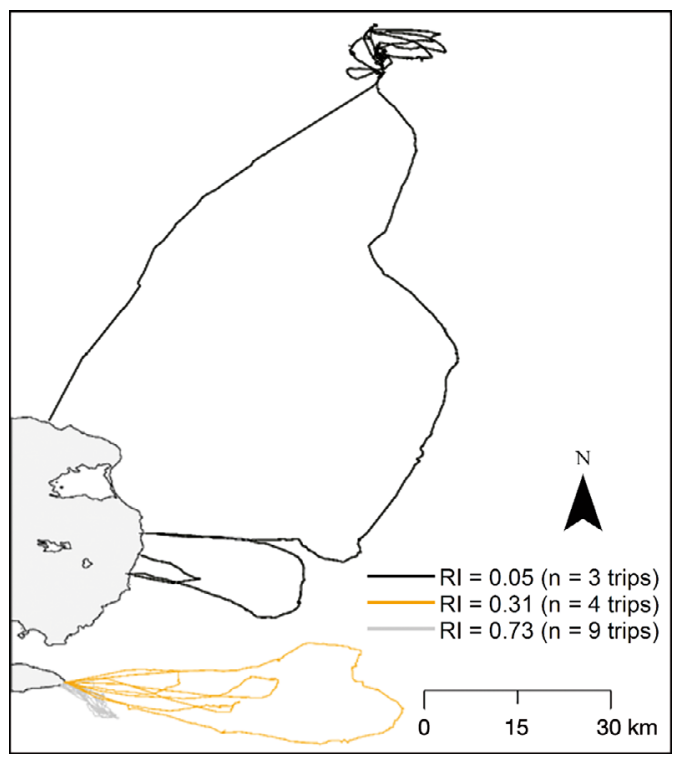

Fig. 3. Representative examples for 3 individual gentoo penguins Pygoscelis papua of spatial use and repeatability index (RI) for a highly repeatable individual (grey), a moderately repeatable one (orange) and an individual with limited repeatability (black) among instrumented birds at Pointe Suzanne and Estacade during the crèche period in December 2014 to January 2015 


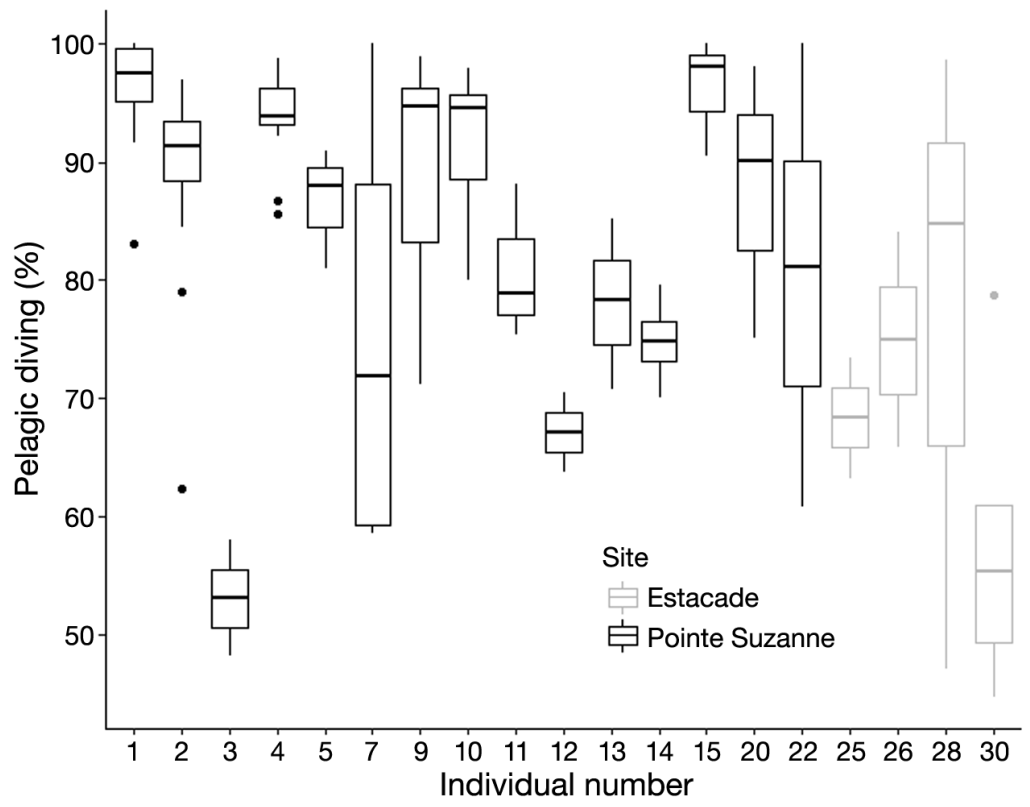

Fig. 4. Boxplots for the proportion of pelagic diving performed in subsequent trips by individual gentoo penguins Pygoscelis papua instrumented at Pointe Suzanne and Estacade during the crèche period in December 2014 to January 2015. Bold horizontal line: median of the distribution; box: interquartile range, IQR (first quartile Q1 to third quartile Q3); whiskers: (Q1 + $1.5 \times \mathrm{IQR}$ ) to $(\mathrm{Q} 3+1.5 \times \mathrm{IQR})$; points: outliers

\section{Stable isotope values and link with foraging metrics}

Tissue isotope values varied widely among individuals, with $\delta^{13} \mathrm{C}$ and $\delta^{15} \mathrm{~N}$ ranges of 4.0 and $5.8 \%$ in blood and 4.2 and $4.4 \%$ in feathers, respectively (Table 7). Values for $\delta^{13} \mathrm{C}$ and $\delta^{15} \mathrm{~N}$ co-varied positively in both tissues (linear regression: $F_{1,23}=31.94, \mathrm{R}^{2}=-0.56, \mathrm{p}<0.001$ and $F_{1,22}=38.72, \mathrm{R}^{2}=-0.62, \mathrm{p}<0.001$ in blood and feathers, respectively; Fig. 5). There was no significant difference between the sexes in their $\delta^{13} \mathrm{C}$ values, but males had higher $\delta^{15} \mathrm{~N}$ values in blood and feathers (linear mixed effects models: $t_{23}=$ $3.4, \mathrm{p}=0.002$ and $t_{23}=0.9, \mathrm{p}=0.4$, for nitrogen and carbon, respectively). Site did not influence $\delta^{15} \mathrm{~N}$ and $\delta^{13} \mathrm{C}$ values $\left(t_{23}=-0.6, \mathrm{p}=0.5\right.$, and $t_{23}=-0.5, \mathrm{p}=0.6$, respectively). Isotopic values in blood and feathers were positively and linearly correlated. Excluding an outlier (that was depicted by a preliminary statistical analysis) increased the strength of the relationships
Table 6. Variance component analysis of dive depths, total distances travelled and bearings to most distal point for gentoo penguins Pygoscelis papua instrumented at Pointe Suzanne and Estacade (Kerguelen Islands, Indian Ocean) during the crèche period in December 2014 to January 2015. $\sigma^{2} \%$ is an estimate of individual specialisation (see 'Materials and methods' for details)

\begin{tabular}{|lccc|}
\hline Variance component & $\sigma^{2}$ & $\Sigma$ & $\sigma^{2} \%$ \\
\hline Maximum range & & & \\
Individual & 127.6 & 11.3 & 13.7 \\
Residual & 802.6 & 28.3 & 86.3 \\
Bearings to most distal point & & & \\
Individual & 1572.7 & 39.7 & 52.9 \\
Residual & 1397.6 & 37.4 & 47.1 \\
Mean bottom depth (null model) & & & \\
Individual & 244.2 & 15.6 & 6.2 \\
Trip & 62.6 & 7.9 & 1.6 \\
Residual & 3612.8 & 60.1 & 92.2 \\
Mean bottom depth (model with mass) & & \\
Individual & 150.9 & 12.3 & 4.0 \\
Trip & 62.6 & 7.9 & 1.6 \\
Residual & 3612.4 & 60.1 & 94.4 \\
Proportion of pelagic diving (null model) & & \\
Individual & 166.4 & 12.9 & 67.5 \\
Residual & 80.1 & 9.0 & 32.5 \\
Proportion of pelagic diving (model with mass) & \\
Individual & 33.5 & 5.8 & 51.3 \\
Residual & 31.9 & 5.6 & 48.7 \\
\hline
\end{tabular}

Table 7. Summary of stable isotope values for gentoo penguins Pygoscelis papua sampled at Pointe Suzanne and Estacade (Kerguelen Islands, Indian Ocean) in December 2014 to January 2015; F: female, M: male, -: unsexed, NA: missing data

\begin{tabular}{|lccccc|}
\hline Bird & Sex & $\begin{array}{c}\text { Blood } \\
\delta C^{13}\end{array}$ & $\begin{array}{c}\text { Blood } \\
\delta \mathrm{N}^{15}\end{array}$ & $\begin{array}{c}\text { Feather } \\
\delta \mathrm{C}^{13}\end{array}$ & $\begin{array}{c}\text { Feather } \\
\delta \mathrm{N}^{15}\end{array}$ \\
\hline 4 & $\mathrm{~F}$ & -18.76 & 11.49 & -18.03 & 11.99 \\
7 & $\mathrm{~F}$ & -18.25 & 10.93 & -18.7 & 12.68 \\
9 & $\mathrm{~F}$ & -17.83 & 12.55 & -15.52 & 13.42 \\
10 & $\mathrm{~F}$ & -19.05 & 11.38 & -18.37 & 12.57 \\
13 & $\mathrm{~F}$ & -20.11 & 8.44 & -19.10 & 11.64 \\
15 & $\mathrm{~F}$ & -19.16 & 9.95 & -19.06 & 12.33 \\
20 & $\mathrm{~F}$ & -20.18 & 9.57 & -19.28 & 11.78 \\
22 & $\mathrm{~F}$ & -19.9 & 8.83 & -15.03 & 14.03 \\
24 & $\mathrm{~F}$ & -16.98 & 10.86 & -16.75 & 12.97 \\
& $\mathrm{M}$ & -18.68 & 11.70 & $\mathrm{NA}$ & $\mathrm{NA}$ \\
2 & $\mathrm{M}$ & -16.86 & 13.55 & -15.09 & 15.02 \\
3 & $\mathrm{M}$ & -19.00 & 12.33 & -16.90 & 14.66 \\
5 & $\mathrm{M}$ & -19.44 & 12.50 & -17.18 & 14.12 \\
6 & $\mathrm{M}$ & -18.57 & 11.90 & -17.97 & 12.66 \\
11 & $\mathrm{M}$ & -19.05 & 11.76 & -18.19 & 13.22 \\
12 & $\mathrm{M}$ & -19.46 & 11.02 & -18.17 & 13.05 \\
14 & $\mathrm{M}$ & -18.49 & 11.26 & -17.71 & 13.39 \\
17 & $\mathrm{M}$ & -18.63 & 11.83 & -18.28 & 13.24 \\
19 & $\mathrm{M}$ & -18.11 & 12.67 & -17.55 & 14.03 \\
23 & $\mathrm{M}$ & -19.98 & 10.29 & -19.17 & 12.62 \\
18 & - & $\mathrm{NA}$ & $\mathrm{NA}$ & -18.72 & 11.09 \\
27 & $\mathrm{~F}$ & -20.30 & 8.43 & -18.94 & 12.40 \\
29 & $\mathrm{~F}$ & -20.14 & 7.95 & -18.59 & 11.86 \\
25 & $\mathrm{M}$ & -19.30 & 11.62 & -17.88 & 12.79 \\
30 & $\mathrm{M}$ & -16.27 & 13.75 & -15.69 & 15.47 \\
33 & $\mathrm{M}$ & -19.44 & 10.74 & -18.71 & 12.78 \\
26 & - & $\mathrm{NA}$ & $\mathrm{NA}$ & -18.82 & 12.32 \\
28 & - & $\mathrm{NA}$ & $\mathrm{NA}$ & -18.03 & 13.39 \\
& & & & & \\
\hline & & & & & \\
\end{tabular}



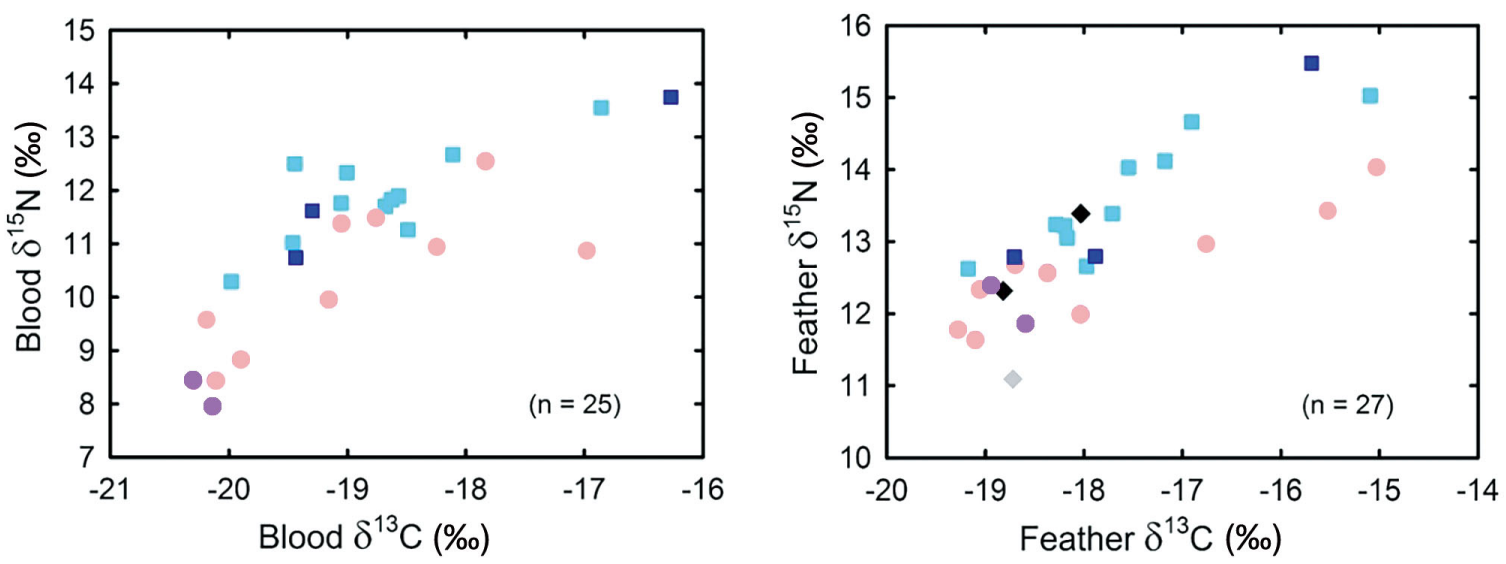

Fig. 5. Relationship between stable isotope values in carbon and nitrogen in blood and in feathers of gentoo penguins $P y-$ goscelis papua sampled at Pointe Suzanne and Estacade during the crèche period in December 2014 to January 2015 (light blue squares = males from Pointe Suzanne, pink circles = females from Pointe Suzanne, dark blue squares = males from Estacade, purple circles $=$ females from Estacade, grey diamond $=1$ unsexed bird from Pointe Suzanne, black diamonds $=2$ unsexed birds from Estacade)

that explained 67 and $70 \%$ of the inter-individual $\delta^{13} \mathrm{C}$ and $\delta^{15} \mathrm{~N}$ variations, respectively (Fig. 6).

There was no relationship between maximum distances reached and blood $\delta^{15} \mathrm{~N}$ or $\delta^{13} \mathrm{C}$ values (linear mixed effects model: $t_{18}=0.1, \mathrm{p}=0.9$, and $t_{18}=-1.1$, $p=0.3$ ). This was also the case for stable isotope values and bearings to the most distal point (linear mixed effects model: $t_{18}=-0.2, \mathrm{p}=0.9$, and $t_{18}=0.1, \mathrm{p}=0.9$, respectively). Lastly, $\delta^{15} \mathrm{~N}$ or $\delta^{13} \mathrm{C}$ values were not influenced by repeatability in spatial use (linear mixed effects model: $t_{10}=1.0, \mathrm{p}=0.3$, and $t_{10}=1.0, \mathrm{p}=$ 0.3 , respectively) or body condition (linear mixed effects model: $t_{11}=1.9, \mathrm{p}=0.1$, and $t_{11}=1.8, \mathrm{p}=0.1$, respectively).

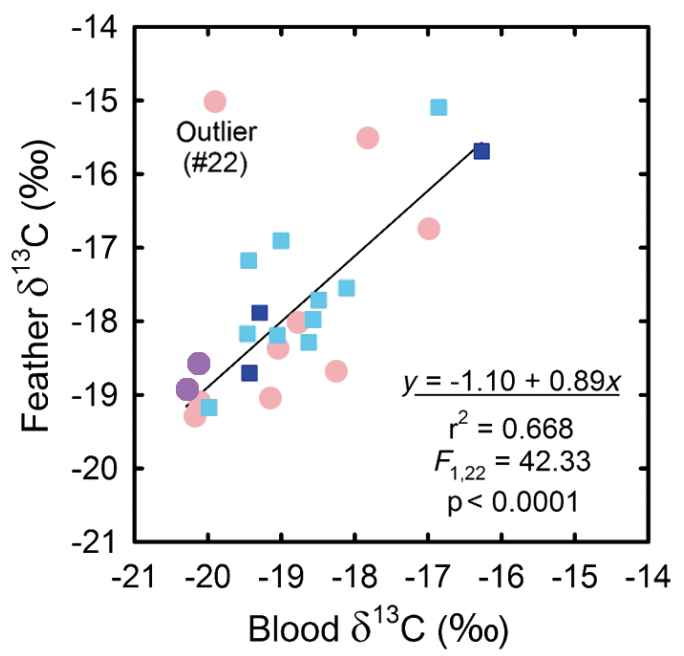

\section{DISCUSSION}

The salient findings of this study concerning an opportunistic coastal forager, the gentoo penguin, can be summarized as follows. (1) Individuals exhibited very large inter- and intra-individual variation in spatial use and diving behaviour. Heavy individuals tended to dive deeper, perform more benthic dives and travel farther. (2) Despite the large intraindividual variation in foraging, some consistency in bearing, proportion of pelagic and night diving, maximum ranges and dive depths was observed in approximately a third of individuals. Foraging behaviour and behavioural consistency were not influ-

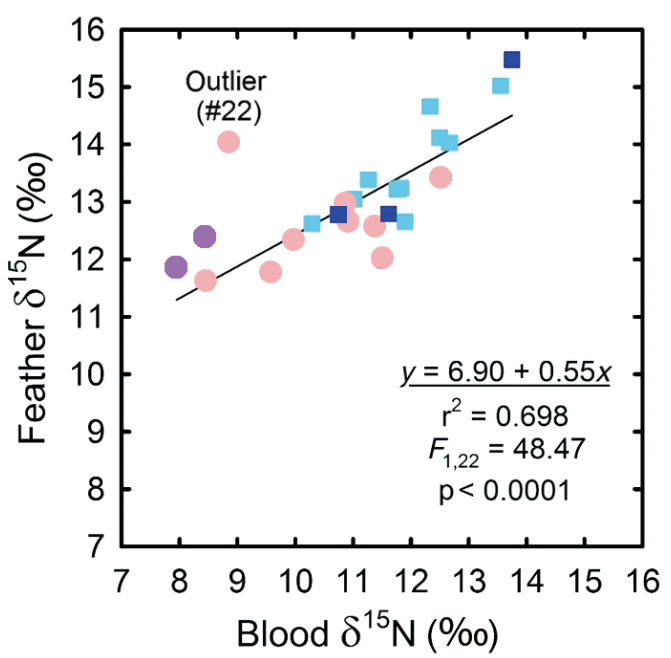

Fig. 6. Correlations between stable isotope values in blood and feather for carbon and nitrogen in gentoo penguins $P y g o s c e l i s$ papua $(\mathrm{n}=24)$ sampled at Pointe Suzanne and Estacade during the crèche period in December 2014 to January 2015 (light blue squares = males from Pointe Suzanne, pink circles = females from Pointe Suzanne, dark blue squares = males from Estacade, purple circles $=$ females from Estacade) 
enced by sex and site. (3) There were large interindividual variations in stable isotope values, and dietary specialisations were present and maintained outside of the single breeding season sampled.

As inshore foragers, gentoos are known to strongly differ in their foraging behaviour according to the local environment (Lescroël \& Bost 2005). Our first prediction was that instrumented individuals would differ greatly in foraging metrics among colonies and among individuals of the same colony. In the present study, site did not seem to influence foraging metrics. However, within a single colony, birds exhibited a large inter-individual variation in foraging behaviour, with some birds conducting very short trips within 5 to $10 \mathrm{~km}$ of the colony while others travelled to areas 120 to $140 \mathrm{~km}$ away. The more pelagic individuals performed up to half of their dives at night during short trips, while more benthic foragers dived predominantly during the day and reached greater depths, regardless of colony. This is consistent with other studies reporting that this species has high behavioural flexibility over its wide range (Wilson et al. 1991, Robinson \& Hindell 1996, Miller et al. 2009, Kokubun et al. 2010). Such flexible foraging habits likely provide a buffer against changes in prey availability and distribution in a limited, coastal environment (Lescroël \& Bost 2005, Miller et al. 2009), as shown in other inshore foragers (Hoskins et al. 2008, Saraux et al. 2011, Camprasse et al. 2017).

In the present study, some of the individuals performed trips longer (up to $5.6 \mathrm{~d}$ ) than previously reported during the crèche period in gentoos on Kerguelen Island (on average $1.3 \mathrm{~d}$ in Estacade, Lescroël et al. 2009). It is possible that some of these birds abandoned breeding during the study, as continued provisioning status could not be determined upon recapture for all birds. However, a third of birds known to still be provisioning chicks at the end of the study conducted such long trips. The large interindividual variation in foraging behaviour observed in instrumented birds could be related to inter-individual variation in morphology (Bost \& Jouventin 1990, this study). Indeed, individuals with higher body mass tended to travel farther, dive deeper and perform more benthic dives, contributing to the observed inter-individual differences in foraging. Differences in dive patterns, associated with larger oxygen stores in heavier birds, have been reported in other diving birds (Mori 1998, Cook et al. 2013).

We predicted that behavioural consistency would be detected in instrumented individuals, as numerous populations considered generalists have actually be shown to be comprised of individual specialists
(Woo et al. 2008, Araújo et al. 2011, Loxdale et al. 2011, Layman \& Allgeier 2012, Fodrie et al. 2015). In the present study, at the population level, individual specialisations in foraging metrics were low to moderate, with bearings to most distal locations and the proportion of pelagic diving exhibiting the highest repeatability. This suggests that gentoos stay consistent in some aspects of their foraging behaviour, which may help to reduce intra-specific competition and/or may allow individuals to catch prey they can easily handle and digest (Bolnick et al. 2003, Estes et al. 2003). This seems particularly relevant in inshore foragers, as they are restricted in their foraging range (Cook et al. 2006, Ratcliffe et al. 2013, Harris et al. 2014).

However, a significant degree of behavioural consistency at the population level does not mean that all individuals are consistent (Woo et al. 2008, Ceia et al. 2012). Indeed, we observed a large variation in the degree of individual consistency in spatial use and dive behaviour between instrumented individuals. While some birds exhibited similar foraging strategies over the course of multiple consecutive trips, others did not. For example, some individuals displayed consistency in the proportion of pelagic diving from one trip to the next while others were able to switch from being mostly benthic on one trip to being entirely pelagic. This highlights the need to sample multiple trips to obtain a more accurate description of a bird's foraging behaviour, particularly in inshore foragers which may exhibit behavioural plasticity (Saraux et al. 2011, Carpenter-Kling et al. 2017). The large inter- and intra-individual variation in foraging behaviour discussed here might contribute to gentoos having stable or expanding populations in parts of their range (e.g. Antarctic Peninsula), where sympatrically breeding penguin species, more dependent on specific resources such as Antarctic krill, experience strong population declines (Miller et al. 2009, Polito et al. 2015).

Our third prediction was that individuals displaying higher consistency in foraging behaviour would have reduced horizontal and vertical distances travelled, and higher body conditions as individual specialisations are thought to improve foraging efficiency (Watanuki 1992, Voslamber et al. 1995, Annett \& Pierotti 1999, Golet et al. 2000, Votier et al. 2004). Contrary to this prediction, no difference in distance travelled (per hour) or body condition was found between consistent and non-consistent individuals in the present study. Thus, it seems that instrumented individuals adopted different strategies based on intrinsic factors (i.e. morphology, prey preferences, etc.), ultimately 
resulting in different repeatability indices. Indeed, the heavier, more benthic individuals performed more distant and longer trips, and such trips were less repeatable within the timeframe of the study.

Generally, it is unclear whether specialists perform better than generalists, as contradictory results have been reported in the literature (Golet et al. 2000, Votier et al. 2004, Ceia et al. 2012, Dehnhard et al. 2016). Our findings are in agreement with results on a long-distance forager, the wandering albatross Diomedea exulans, demonstrating that specialist and generalist individuals had similar levels of body condition (Ceia et al. 2012). No effect of specialisation on reproductive outcomes has been detected in other bird species (Votier et al. 2004, Katzner et al. 2005, Dehnhard et al. 2016). Indeed, even though generalists may deliver somewhat less energy per day, specialisation may not have an impact on measures of evolutionary fitness (Woo et al. 2008). In contrast, other studies on gulls, cormorants, guillemots and skuas have shown specialists to have higher reproductive success, food delivery rates, chick condition or adult survival (Watanuki 1992, Voslamber et al. 1995, Annett \& Pierotti 1999, Golet et al. 2000, Votier et al. 2004). In gentoos, individual specialisations in foraging behaviour may be linked with intrinsic factors, and may be more or less advantageous depending on prey availability, with generalists performing better when food availability is low.

Lastly, in agreement with our second prediction, long-term dietary consistency was detected in the birds sampled. Stable isotope values in blood and feathers in breeding gentoos were positively correlated, indicating that dietary specialisations are maintained outside of the breeding season. This is consistent with recent stomach contents and stable isotope analysis studies on the diet of gentoos, indicating that they may not be as opportunistic as previously thought (Clausen et al. 2005, Polito et al. 2015). Within generalist populations, 2 types can be found: type 'A' generalists, when individuals all take a wide range of food types; and type ' $\mathrm{B}$ ' generalists, when individuals each specialise on a different range of food types (Bearhop et al. 2004). The results from our study, documenting a large inter-individual variation in diet, matching the high inter-individual variation in foraging behaviour, and documenting the fact that instrumented birds tend to display a similar feeding ecology in the breeding and inter-breeding seasons, seem to indicate that gentoos at the studied site are type ' $\mathrm{B}$ ' generalists.

The results of the present study should be interpreted with caution for two main reasons: the large difference in sample sizes between colonies where deployments were performed, and the potentially poor environmental conditions the instrumented birds experienced, seemingly leading to low prey availability as judged by the low number of chicks raised by gentoos and sympatrically breeding shags (E. C. M. Camprasse pers. obs.). More data are needed from Estacade to confirm the lack of a site effect on the gentoos' foraging behaviour and feeding ecology. Factors including a high incidence of night diving and long trip durations could reflect poor environmental conditions in the 2014/2015 breeding season, forcing penguins to forage in suboptimal conditions. This is consistent with poor breeding success on Kerguelen Islands during deployments compared with normal years, with brooders losing chicks at the crèche stage (E. C. M. Camprasse pers. obs.). In the present study, shallow nighttime dives were observed in the more pelagic individuals, probably to allow them to take advantage of pelagic prey distributed near the surface at night during their diurnal vertical migration. Night/ twilight diving has been recorded in pygoscelid penguins including gentoos (Croxall et al. 1988, Williams \& Rodwell 1992, Robinson \& Hindell 1996) and other penguin species (Schiavini \& Rey 2004, Rey et al. 2012), but was thought to be uncommon in such visual predators (Williams 1995, Bost et al. 2002). Lastly, low prey availability, linked with the seemingly poor environmental conditions experienced by the birds instrumented in the present study, could increase the degree of individual specialisation, as individuals are forced to add different alternative prey not consumed by conspecifics to their diet (Svanbäck \& Bolnick 2007, Tinker et al. 2008).

In summary, we showed that gentoo penguins on Kerguelen Island exhibited large inter- and intraindividual variations in foraging behaviour. These may provide gentoos greater resilience to buffer against changes in prey availability and fast changing environmental conditions, especially as their foraging range is usually limited (Lescroël \& Bost 2005, Polito et al. 2015). However, within this context, gentoos still exhibit individual specialisation, helping them reduce intra-specific competition and/or increasing their foraging efficiency (dit Durell 2000, Masello et al. 2013). Dietary specialisations outside of a single breeding season were also highlighted, suggesting that gentoo penguins are type 'B' generalists. The next step to understand the consequences of individual specialisations would be to look at the link between behavioural consistency and reproductive output, which could not be done in this study due to 
logistical constraints. In order to fully understand the effects of individual consistency of parents on their offspring, researchers should also aim at obtaining information on both partners of breeding pairs (Polito et al. 2015). In the future, repetitive sampling of the same individuals across stages of the same breeding season and across years will help to characterize the persistence of dietary specialisations at different temporal scales in seabirds.

Acknowledgements. This study was approved by the ethics committee of the French Polar Institute (Program IPEV 394 OIPLO, principal investigator C.-A.B.). All animals in this study were handled in accordance with its guidelines. The work was supported financially and logistically by the French Polar Institute and the Terres Australes et Antarctiques Françaises. We thank fieldwork volunteers, including Ayala Loisel, Elie Gaget, Florian Orgeret, Joris Laborie and Martin Delpuech. We also acknowledge the help of David Pinaud, Matthew Symonds and Andrew Hoskins for assistance with statistical analyses. Lastly, we thank Maud Brault-Favrou and Gaël Guillou for their contribution to sample preparation and isotopic analysis, respectively.

\section{LITERATURE CITED}

Agostinelli C, Lund U (2011) R package circular: circular statistics (version 0.4-3). http://CRAN.R-project.org/ package $=$ circular

Anderson O, Phillips R, Shore R, McGill R, McDonald R, Bearhop $S$ (2009) Diet, individual specialisation and breeding of brown skuas (Catharacta antarctica lonnbergi): an investigation using stable isotopes. Polar Biol 32:27-33

Annett CA, Pierotti R (1999) Long-term reproductive output in western gulls: consequences of alternate tactics in diet choice. Ecology 80:288-297

Araújo MS, Bolnick DI, Layman CA (2011) The ecological causes of individual specialisation. Ecol Lett 14:948-958

Bates D, Maechler M, Bolker B, Walker S (2014) lme4: linear mixed-effects models using Eigen and S4. R package version 1.1-6.

Baylis AMM, Orben RA, Pistorius P, Brickle P, Staniland I, Ratcliffe N (2015) Winter foraging site fidelity of king penguins breeding at the Falkland Islands. Mar Biol 162: 99-110

Bearhop S, Adams CE, Waldron S, Fuller RA, MacLeod H (2004) Determining trophic niche width: a novel approach using stable isotope analysis. J Anim Ecol 73:1007-1012

Bearhop S, Phillips RA, McGill R, Cherel Y, Dawson DA, Croxall JP (2006) Stable isotopes indicate sex-specific and long-term individual foraging specialisation in diving seabirds. Mar Ecol Prog Ser 311:157-164

Bolnick DI, Svanbäck R, Fordyce JA, Yang LH, Davis JM, Hulsey CD, Forister ML (2003) The ecology of individuals: incidence and implications of individual specialization. Am Nat 161:1-28

Bost CA, Jouventin P (1990) Evolutionary ecology of Gentoo penguin Pygoscelis papua. In: Davis LS, Darby JT (eds) Penguin biology. Academic Press, New York, NY, p 85-112
Bost CA, Zorn T, Le Maho Y, Duhamel G (2002) Feeding of diving predators and diel vertical migration of prey: King penguins' diet versus trawl sampling at Kerguelen Islands. Mar Ecol Prog Ser 227:51-61

Calenge C (2015) Analysis of animal movements in R: the adehabitatLT Package. http://CRAN.R-project.org/ package $=$ adehabitatLT

Camprasse ECM, Cherel Y, Arnould JPY, Hoskins AJ, Bost CA (2017) Combined bio-logging and stable isotopes reveal individual specialisations in a benthic coastal seabird, the Kerguelen shag. PLOS ONE 12:e0172278

* Carpenter-Kling T, Handley JM, Green DB, Reisinger RR, Makhado AB, Crawford RJ, Pistorius PA (2017) A novel foraging strategy in gentoo penguins breeding at subAntarctic Marion Island. Mar Biol 164:33

Ceia FR, Ramos JA (2015) Individual specialization in the foraging and feeding strategies of seabirds: a review. Mar Biol 162:1923-1938

Ceia FR, Phillips RA, Ramos JA, Cherel Y, Vieira RP, Richard P, Xavier JC (2012) Short- and long-term consistency in the foraging niche of wandering albatrosses. Mar Biol 159:1581-1591

* Cherel Y, Hobson KA (2007) Geographical variation in carbon stable isotope signatures of marine predators: a tool to investigate their foraging areas in the Southern Ocean. Mar Ecol Prog Ser 329:281-287

* Cherel Y, Hobson KA, Weimerskirch H (2000) Using stableisotope analysis of feathers to distinguish moulting and breeding origins of seabirds. Oecologia 122:155-162

* Cherel Y, Hobson KA, Bailleul F, Groscolas R (2005a) Nutrition, physiology, and stable isotopes: new information from fasting and molting penguins. Ecology 86:2881-2888

* Cherel Y, Hobson KA, Hassani S (2005b) Isotopic discrimination between food and blood and feathers of captive penguins: implications for dietary studies in the wild. Physiol Biochem Zool 78:106-115

Cherel Y, Le Corre M, Jaquemet S, Menard F, Richard P, Weimerskirch $\mathrm{H}$ (2008) Resource partitioning within a tropical seabird community: new information from stable isotopes. Mar Ecol Prog Ser 366:281-291

* Cherel Y, Fontaine C, Richard P, Labatc JP (2010) Isotopic niches and trophic levels of myctophid fishes and their predators in the Southern Ocean. Limnol Oceanogr 55: 324-332

Clausen AP, Arkhipkin AI, Laptikhovsky VV, Huin N (2005) What is out there: diversity in feeding of gentoo penguins (Pygoscelis papua) around the Falkland Islands (Southwest Atlantic). Polar Biol 28:653-662

Cook TR, Cherel Y, Tremblay Y (2006) Foraging tactics of chick-rearing Crozet shags: individuals display repetitive activity and diving patterns over time. Polar Biol 29: 562-569

Cook TR, Lescroël A, Cherel Y, Kato A, Bost CA (2013) Can foraging ecology drive the evolution of body size in a diving endotherm? PLOS ONE 8:e56297

Croxall J, Davis L (1999) Penguins: paradoxes and patterns. Mar Ornithol 27:1-12

* Croxall J, Davis R, O'Connell M (1988) Diving patterns in relation to diet of Gentoo and Macaroni penguins at South Georgia. Condor 90:157-167

Cucherousset J, Acou A, Blanchet S, Britton JR, Beaumont WR, Gozlan RE (2011) Fitness consequences of individual specialisation in resource use and trophic morphology in European eels. Oecologia 167:75-84

Cuervo JJ, Palacios MJ, Barbosa A (2009) Beak colouration 
as a possible sexual ornament in gentoo penguins: sexual dichromatism and relationship to body condition. Polar Biol 32:1305-1314

* Dehnhard N, Eens M, Sturaro N, Lepoint G, Demongin L, Quillfeldt P, Poisbleau M (2016) Is individual consistency in body mass and reproductive decisions linked to individual specialization in foraging behavior in a long-lived seabird? Ecol Evol 6:4488-4501

* Dingemanse NJ, Dochtermann NA (2013) Quantifying individual variation in behaviour: mixed-effect modelling approaches. J Anim Ecol 82:39-54

dit Durell SE (2000) Individual feeding specialisation in shorebirds: population consequences and conservation implications. Biol Rev Camb Philos Soc 75:503-518

* dit Durell SE, Goss-Custard JD, Caldow RW, Malcolm HM, Osborn D (2001) Sex, diet and feeding method-related differences in body condition in the oystercatcher Haematopus ostralegus. Ibis 143:107-119

Estes J, Riedman M, Staedler M, Tinker M, Lyon B (2003) Individual variation in prey selection by sea otters: patterns, causes and implications. J Anim Ecol 72:144-155

Fodrie FJ, Yeager LA, Grabowski JH, Layman CA, Sherwood GD, Kenworthy MD (2015) Measuring individuality in habitat use across complex landscapes: approaches, constraints, and implications for assessing resource specialization. Oecologia 178:75-87

* Golet GH, Kuletz KJ, Roby DD, Irons DB (2000) Adult prey choice affects chick growth and reproductive success in pigeon guillemots. Auk 117:82-91

Grolemund G, Wickham H (2011) Dates and times made easy with lubridate. J Stat Softw 40:1-25

*Harris S, Rey AR, Zavalaga C, Quintana F (2014) Strong temporal consistency in the individual foraging behaviour of imperial shags Phalacrocorax atriceps. Ibis 156: 523-533

Hindell M (1989) The diet of gentoo penguins Pygoscelis papua at Macquarie Island: winter and early breeding season. Emu 89:71-78

Hoskins AJ, Dann P, Ropert-Coudert Y, Kato A, Chiaradia A, Costa DP, Arnould JP (2008) Foraging behaviour and habitat selection of the little penguin Eudyptula minor during early chick rearing in Bass Strait, Australia. Mar Ecol Prog Ser 366:293-303

Jaeger A, Connan M, Richard P, Cherel Y (2010) Use of stable isotopes to quantify seasonal changes of trophic niche and levels of population and individual specialisation in seabirds. Mar Ecol Prog Ser 401:269-277

Katzner TE, Bragin EA, Knick ST, Smith AT (2005) Relationship between demographics and diet specificity of Imperial Eagles Aquila heliaca in Kazakhstan. Ibis 147: 576-586

Kernaléguen L, Arnould JPY, Guinet C, Cherel Y (2015) Determinants of individual foraging specialization in large marine vertebrates, the Antarctic and Subantarctic fur seals. J Anim Ecol 84:1081-1091

Kernaléguen L, Dorville N, Ierodiaconou D, Hoskins AJ and others (2016) From video recordings to whisker stable isotopes: a critical evaluation of timescale in assessing individual foraging specialisation in Australian fur seals. Oecologia 180:657-670

Kokubun N, Takahashi A, Mori Y, Watanabe S, Shin HC (2010) Comparison of diving behavior and foraging habitat use between chinstrap and gentoo penguins breeding in the South Shetland Islands, Antarctica. Mar Biol 157: 811-825
Layman CA, Allgeier JE (2012) Characterizing trophic ecology of generalist consumers: a case study of the invasive lionfish in The Bahamas. Mar Ecol Prog Ser 448:131-141

Lê S, Josse J, Husson F (2008) FactoMineR: an R package for multivariate analysis. J Stat Softw 25:1-18

ㄴescroël A, Bost CA (2005) Foraging under contrasting oceanographic conditions: the gentoo penguin at Kerguelen Archipelago. Mar Ecol Prog Ser 302:245-261

Lescroël A, Ridoux V, Bost CA (2004) Spatial and temporal variation in the diet of the gentoo penguin (Pygoscelis papua) at Kerguelen Islands. Polar Biol 27:206-216

Lescroël A, Bajzak C, Bost CA (2009) Breeding ecology of the gentoo penguin Pygoscelis papua at Kerguelen Archipelago. Polar Biol 32:1495-1505

Loxdale HD, Lushai G, Harvey JA (2011) The evolutionary improbability of 'generalism' in nature, with special reference to insects. Biol J Linn Soc 103:1-18

Luque SP (2007) Diving behaviour analysis in R. R News 7 : $8-14$

Lynch H (2013) Gentoo penguin (Pygoscelis papua). In: Borboroglu GP, Boersma PD (eds) Penguins: natural history and conservation. University of Washington Press, Washington, DC, p 73-90

Masello JF, Wikelski M, Voigt CC, Quillfeldt P (2013) Distribution patterns predict individual specialization in the diet of dolphin gulls. PLOS ONE 8:e67714

*Matich P, Heithaus MR, Layman CA (2011) Contrasting patterns of individual specialization and trophic coupling in two marine apex predators. J Anim Ecol 80:294-305

* Miller AK, Karnovsky NJ, Trivelpiece WZ (2009) Flexible foraging strategies of gentoo penguins Pygoscelis papua over 5 years in the South Shetland Islands, Antarctica. Mar Biol 156:2527-2537

Mori Y (1998) Optimal choice of foraging depth in divers. J Zool (Lond) 245:279-283

* Paradis E, Claude J, Strimmer K (2004) APE: analyses of phylogenetics and evolution in $\mathrm{R}$ language. Bioinformatics 20:289-290

Pebesma E, Bivand R (2005) Classes and methods for spatial data in R. R News 5:9-13

Polito MJ, Abel S, Tobias CR, Emslie SD (2011) Dietary isotopic discrimination in gentoo penguin (Pygoscelis papua) feathers. Polar Biol 34:1057-1063

* Polito MJ, Trivelpiece WZ, Patterson WP, Karnovsky NJ, Reiss CS, Emslie SD (2015) Contrasting specialist and generalist patterns facilitate foraging niche partitioning in sympatric populations of Pygoscelis penguins. Mar Ecol Prog Ser 519:221-237

R Core Team (2015) R: a language and environment for statistical computing. R Foundation for Statistical Computing, Vienna

Ratcliffe N, Takahashi A, O'Sullivan C, Adlard S, Trathan PN, Harris MP, Wanless S (2013) The roles of sex, mass and individual specialisation in partitioning foragingdepth niches of a pursuit-diving predator. PLOS ONE 8: e79107

Rey AR, Pütz K, Scioscia G, Lüthi B, Schiavini A (2012) Sexual differences in the foraging behaviour of Magellanic penguins related to stage of breeding. Emu 112:90-96

* Robinson SA, Hindell MA (1996) Foraging ecology of gentoo penguins Pygoscelis papua at Macquarie Island during the period of chick care. Ibis 138:722-731

Saraux C, Robinson-Laverick SM, Le Maho Y, Ropert-Coudert Y, Chiaradia A (2011) Plasticity in foraging strategies of inshore birds: how little penguins maintain body 
reserves while feeding offspring. Ecology 92:1909-1916

Schiavini A, Rey AR (2004) Long days, long trips: foraging ecology of female rockhopper penguins Eudyptes chrysocome chrysocome at Tierra del Fuego. Mar Ecol Prog Ser 275:251-262

Stephens DW, Krebs JR (1986) Foraging theory. Princeton University Press, Princeton, NJ

Sumner MD (2009) trip: tools for the analysis of animal track data (R package version 1.1-17). http://CRAN.R-project. org/package=trip

Svanbäck R, Bolnick DI (2007) Intraspecific competition drives increased resource use diversity within a natural population. Proc R Soc Lond B Biol Sci 274:839-844

Svanbäck R, Persson L (2009) Population density fluctuations change the selection gradient in Eurasian perch. Am Nat 173:507-516

Tinker MT, Bentall G, Estes JA (2008) Food limitation leads to behavioral diversification and dietary specialization in sea otters. Proc Natl Acad Sci USA 105:560-565

Voslamber B, Platteeuw M, Van Eerden M (1995) Solitary foraging in sand pits by breeding cormorants Phalacrocorax carbo sinensis: Does specialised knowledge about fishing sites and fish behaviour pay off? Ardea 83: 199-212

Votier SC, Bearhop S, Ratcliffe N, Furness RW (2004) Reproductive consequences for great skuas specializing as

Editorial responsibility: Sue Lewis (Guest Editor),

Penicuik, UK seabird predators. Condor 106:275-287

*Watanuki Y (1992) Individual diet difference, parental care and reproductive success in slaty-backed gulls. Condor 94:159-171

Williams TD (1995) The penguins; Spheniscidae. Oxford University Press, Oxford

*Williams T, Rodwell S (1992) Annual variation in return rate, mate and nest-site fidelity in breeding gentoo and Macaroni penguins. Condor 94:636-645

Wilson RP, Grant WS, Duffy DC (1986) Recording devices on free-ranging marine animals: Does measurement affect foraging performance? Ecology 67:1091-1093

*Wilson RP, Culik B, Spairani HJ, Coria NR, Adelung D (1991) Depth utilization by penguins and gentoo penguin dive patterns. J Ornithol 132:47-60

Woehler E (1995) Consumption of Southern Ocean marine resources by penguins. In: Dann P, Norman I, Reilly P (eds) The penguins: ecology and management. Surrey Beatty \& Sons, Chipping Norton, p 266-294

* Woo KJ, Elliott KH, Davidson M, Gaston AJ, Davoren GK (2008) Individual specialization in diet by a generalist marine predator reflects specialization in foraging behaviour. J Anim Ecol 77:1082-1091

Zuur A, Ieno E, Walker N, Saveliev A, Smith G (2009) Mixed effects models and extensions in ecology with $R$. Springer Science and Business Media, New York, NY

Submitted: November 28, 2016; Accepted: April 10, 2017

Proofs received from author(s): June 12, 2017 